\title{
The Proceedings
}

\section{of the Nutrition}

Society

VOLUME 55 NUMBER 2 JULY 1996 


\title{
EDITED FOR THE NUTRITION SOCIETY
}

\author{
K. M. YOUNGER \\ Proceedings Editor \\ P. J. A. SHEEHY \\ Proceedings of the Irish Section \\ EDITORIAL STAFF \\ I. E. Sambrook (Executive Editor) D. V. Mitchelmore (Assistant Executive Editor) \\ C. T. Hughes, S. M. Kingman (Technical Editors)
}

The Nutrition Society has as its object the advancement of the scientific study of nutrition and its application to the maintenance of human and animal health.

Application for membership is invited from anyone whose work has contributed to the scientific knowledge of nutrition, whether such work has been in the laboratory, the field or the clinic, and whether experimental, clinical, agricultural or statistical in nature. There is also a student membership scheme with reduced subscriptions.

Particulars of The Nutrition Society and application forms for membership may be had from the Honorary Secretary, Dr. J. C. Mathers, The Nutrition Society, 10 Cambridge Court, 210 Shepherds Bush Road, London W6 7NJ.

The Proceedings of the Nutrition Society, published by Cambridge University Press, in part record meetings of the Symposium type, at which experts in a particular field are invited by Council to make contributions on specific parts of it and at which general discussion follows these invited contributions. The meetings also include sessions at which original communications are presented by members and others. Abstracts of communications accepted at the meetings are published in the Proceedings. The Proceedings are published three times a year.

The British Journal of Nutrition is published monthly by Cambridge University Press for The Nutrition Society, which owns it and controls its publication. It is devoted to reports of original work in all branches of nutrition, the term 'original work' not implying that the papers must invariably be based on new facts. The British Journal of Nutrition does not print reviews of the literature or polemical articles, but the Editorial Board is willing to consider original articles critically re-examining published information and the conclusions drawn from it.

Nutrition Research Reviews, published annually by Cambridge University Press, presents authoritative and critical reviews of research that advance new concepts and encourage fresh thinking on a variety of nutritional problems. The journal's main objective is to encourage the exchange of fundamental ideas on nutritional well-being.

Subscriptions to the Society's Publications. For non-members of the Nutrition Society the subscription including postage (excluding VAT) to Volume 55, 1996 of the Proceedings, is $£ 144$, payable in advance to the Cambridge University Press, The Edinburgh Building, Shaftesbury Road, Cambridge CB2 2RU or to any bookseller. The subscription in USA, Canada and Mexico is US \$264 and enquiries should be addressed to the Cambridge University Press, Journals Department, 40 West 20th Street, New York, NY 10011-4211. EU subscribers (outside the UK) who are not registered for VAT should add VAT at their country's rate. VAT registered subscribers should provide their VAT registration number. All orders must be accompanied by payment. Japanese prices for institutions (including ASP delivery) are available from Kinokuniya Company Ltd, P.O. Box 55, Chitose, Tokyo 156, Japan.

The annual subscription (excluding VAT) to the Journal is $\$ 310$ (US $\$ 576$ in the USA, Canada and Mexico). The subscription (excluding VAT) to Nutrition Research Reviews is $£ 50$ (USA, Canada and Mexico \$90). The price for single issues of the Journal is $£ 27$ (USA, Canada and Mexico \$50). Single issues of the Proceedings are $£ 53$ net (USA, Canada and Mexico \$98), postage extra. POSTMASTER: send address changes in USA; Canada and Mexico to Proceedings of the Nutrition Society, Cambridge University Press, 110 Midland Avenue, Port Chester, New York, NY 10573-4930.

(C) The Nutrition Society, 1996. 